\title{
The preparation for being a researcher in Romania today
}

\author{
Eugen Pămîntaş, ${ }^{1, *}$, and Felicia Veronica Banciu $^{1}$ \\ ${ }^{1}$ Politehnica University of Timişoara, Materials and Manufacturing Engineering Department, 300222, \\ Timişoara, Romania
}

\begin{abstract}
Higher technical education in Romania is organized in three cycles: Bachelor, Masters and $\mathrm{PhD}$. Theoretically, the powers provided by the three levels of education should be in correspondence with the requirements of COR (ISCO-88-COM European Community and the UN: ISCO 88) for generic jobs, specified in previous herewith: production engineer, research engineer, and researcher. This paper explores the last two aspects in order to see to what extent the names of study disciplines and especially their content gives the graduate competences and skills of research. We are looking for causes for which young graduates of master and doctoral especially not find appropriate jobs in the labor market preparation. From the position of academics with experience in teaching the final year of Bachelor and Master levels, trying to answer to the questions: What should we teach, How should we teach? Who should we teach? We train for right people? The answers are tasks for interdisciplinary collective of teachers, researchers and employers. Therefore, without claiming an exhaustive treatment of the matter under discussion, the paper is intended as a call a call to quickly find viable solutions. Where answers are not appropriate, will have to find solutions but the decision in their choice and then their implementation in the short time it is a governmental task.
\end{abstract}

\section{About research methodology}

The authors teaching experience have found that the generic methodology creates some problems, which is why it was considered useful to make some terminological remarks. This is why hereinafter briefly present some considerations regarding the methodology of scientific research, as is almost universally accepted. The purpose of the presentation is to provide support in analyzing the extent to which these concepts are found in the disciplines of master degrees. Master study cycle is declared as the deepening of a narrower field of study and research initiation into it. The next step is continuing the research activity during doctoral studies, which gives graduate researcher attributes to be confirmed by the results of quantitative and qualitative research work at scientific research institutes or universities, public or private.

\footnotetext{
*Corresponding author: eugen.pamintas@upt.ro
} 


\section{Conceptual delimitations}

\subsection{Methodology, method, technique, research tool}

In a broad sense the methodology means all methods used in scientific research or simply the science of researching, (from Greek: metodos- road, path and logos - science).

In fact, through research methodology we understand the existence of at least one discipline in which are developed methods for developing the scientific knowledge and all the elements involved in the research. The fundamental aim of the methodology is to assist in understanding - in terms widest possible - not so much the products of science, but especially the functioning of knowledge process itself.

To be able to fulfill its function, scientific research methodology includes both, the proper definition of the studied field, a number of principles and rules for investigation purposes, the instrumentation of work for collecting and interpret data, strategies for theoretical construction or reconstruction as well as results assessment.

Method - the first use of the term may create some difficulties, therefore, in order to better understand, we offer a classification without claiming an exhaustive treatment:

a) on the criterion time:

-Transversal methods - analysis of phenomena or facts at a time (the status quo, operating parameters or currently indicators, tests etc.).

-Longitudinal methods - analysis of facts or phenomena in their evolution (case study, bibliographic analysis, the study panel etc).

b) by type of the investigation:

- Quantitative methods - with orientation type positivist-explanatory (currently system response on experiment, the basic parameters).

- Qualitative methods - phenomenological orientation, comprehensive (participant observation, meeting the permissible limits, case study, etc.).

- Method of intersection - between the approach combining quantitative and qualitative (analysis overview with links, history analysis of relevant information etc.).

c) by the place in the investigative process:

-Data collection methods (analog, digital, sequential, continuous, etc.).

- Data processing methods (statistical and mathematical, comprehensive analysis etc.).

-Data interpretation methods (inductive, deductive, comparative, causal explanation).

Research technique - is subsumed to a method and represents the manner to use various investigative tools, helping to collect or process data (dynamometers, sensors etc.).

Research tool - is the materialization of a method (measurement sheet is a tool of analog data collection method, observation sheet is a tool for participative observation etc.).

\subsection{Methodological principles of scientific research}

The deployment of scientific research assumes the following general principles:

-The principle of unity between theoretical and empirical. Theoretic presence in empirical research, regardless of its weight, it is often the default form of assumptions that must be acknowledged and explained, before starting the research.

-The principle of unity between understanding (comprehension) and explanation calls into question the relationship between subject and object of knowledge.

- The principle of unity between quantity and quality, require compatible approaches in quantitative and qualitative methods in order to achieve complementarity and interference both in the general epistemological and other particular levels. 
- The principle of unity between the observantand evaluative judgments requires hiring a researcher moral support generally valid values in any field of human knowledge.

\subsection{Assessment of scientific research}

The task of evaluation of scientific research lies primarily those who make them. The evaluation of research is intended to constitute a critical attitude in receiving results, preventing improvisation and misrepresentation, through theoretical elaborations sophisticated to support or promote partisan interests.

Although scientific literature designed to evaluate the scientific research is not too rich, nevertheless the criteria were developed aimed mainly:

-the correctness of of the theoretical framework research;

-the quality of the conceptual analysis and defining the scope of research;

-the adequacy of methods, techniques and working tools to the specific characteristics of the studied object and its operating;

-the validity and reliability of measurement instruments;

-the representativeness of the study object

-the degree of favorability of the conduct of investigations to ensure objectivity;

-the quality of the processing, analysis and interpretation of information;

-the manner of theoretical construction.

Assessment of theoretical and methodological framework is based on the following indicators (top four concerns the theoretical framework and the following, the methodology):

a) appropriate definition of concepts, or scientific validity thereof;

b) the operationalization of concepts to bring to the foreground measurable and relevant indicators;

c) formulation of hypotheses to be a convincing explanatory model and be testable;

d) determining the scale and activity of the research topic;

e) the choice of methods and research techniques in line with the specific objectives pursued and studied field;

f) the tools for working in agreement with the contents topic and defining the operational concepts;

g) the adequacy of research instruments to the characteristics of the subject;

h) evaluating the measurements taken.

Assessing the degree of validity and reliability

a) validity analysis - establishes whether the instruments used mode and capture what was proposed. There are the following types of validity:

- Content validity (internal) - designed to measure the degree to which indicators which supposedly is measured;

- Predictive validity (external) - aims extent to which measurements provide an insight into relations with other measurements and forecasting ability of the subjects;

- Construct validity - refers to the explanatory factors of a particular result obtained by measurement. The extent of this type of validity is given by the manner of correlation between the variables studied.

b) fidelity analysis - targeting the confidence and stability of tools. The degree of fidelity is given the extent to which through measurements, we can get the true values that characterize the manifestation of a phenomenon or social fact. 


\section{Research educations}

Taking in the consideration the strong emphasis on the research in all countries, as an educational endeavor, we were collectively confusing by the lack of engagement with one of the central concepts within the field of education: curriculum.

Rethinking the preparation for research in these terms directs attention to the forms of knowledge in which it is grounded and how these are articulated in the documentation and assessment of the future job.

But curriculum may be about more than this. The special ad hoc group made up of the Conference "Diaspora and his friends" held at the Polytechnic University and West University of Timişoara between 24 to 28 April 2016 under the auspices of the Romanian Presidential Administration, brought together experienced teachers and researchers in a range of countries, and with varying interpretations of 'the researcher curriculum'. As panel we did not speak with one voice, but rather sought to engage each other and our audience with this rich, powerful, contested, difficult and sometimes slippery notion.

As was noted from the start was that an educational curriculum or books published on education for research is more or less nonexistent in Europe and even more in Romania. The Bologna process has had some impact, since it has forced us to articulate the intended learning outcomes of coursework as competencies; this has been a challenge to many of us. But to articulate the curriculum and pedagogies at work in our daily practice demands some reflection. In our department of Material and Manufacturing Engineering (at the University of Timisoara), which hosts three masters fields, advanced materials, industrial engineering and advanced welding technologies, we have agreed to a common structure for quality assurance through the master's program but it does not provide the necessary skills for research training.

The research results must be disseminated. Following this, there is also pressure for writing in English. This means that master students (and by all means, also senior researchers), who do not have English as their mother language, may always feel a step behind. Many of our master or doctoral students have never written anything in English before entering their research or doctoral education. There is a curricular pedagogical challenge there, how to support those writing skills when you are not yourself a native English speaker.

Research education does not occur in a vacuum, but rather is influenced by, among other factors, policies, procedures, global developments, and significant others support services and resources. What may be broadly termed the environment or context in which master and doctoral studies are undertaken have an important bearing on the curriculum. Furthermore, the examination process is a substantial factor in the curriculum, not only as an assessment strategy, but also as a specific process in which the power difference between the candidate and supervisor is particularly evident. Finally, the outcomes and outputs of the research education experience are critical factors which shape the research curriculum [1].

Practitioner research is a process of discovering and framing questions, collecting data, and analyzing data to answer the questions [2].

It is important that practitioner researchers have more than one method of gathering information so that data can be triangulated [3]. Triangulation, which entails the use of multiple data sources to confirm and illuminate one another, is strength of practitioner research as well as of university research [4-6].

Data is analyzed, with an emphasis on finding patterns. Drawing on their prior knowledge and experience, practitioners can then formulate hypotheses about emerging patterns.

The preparation for research activities "involves disciplined inquiry" [7] which means that "studies are intentional and systematically conducted" [8]. 
At the center of this action research plan was curriculum inquiry, "similar to the ways detectives and journalists do their work-asking probing questions that led to finding truth" [9]. Simms goes on to note that focusing on questions, including emphasizing the use of what, how, who, why, where, and when, served to remind teachers that they need to ask these questions in support of creating curriculum that motivates their students to ask questions and investigate issues and events related to culture.

ENVIRONMENT/CONTEXT: Candidates and supervisors interact and learning within a research leaming environment

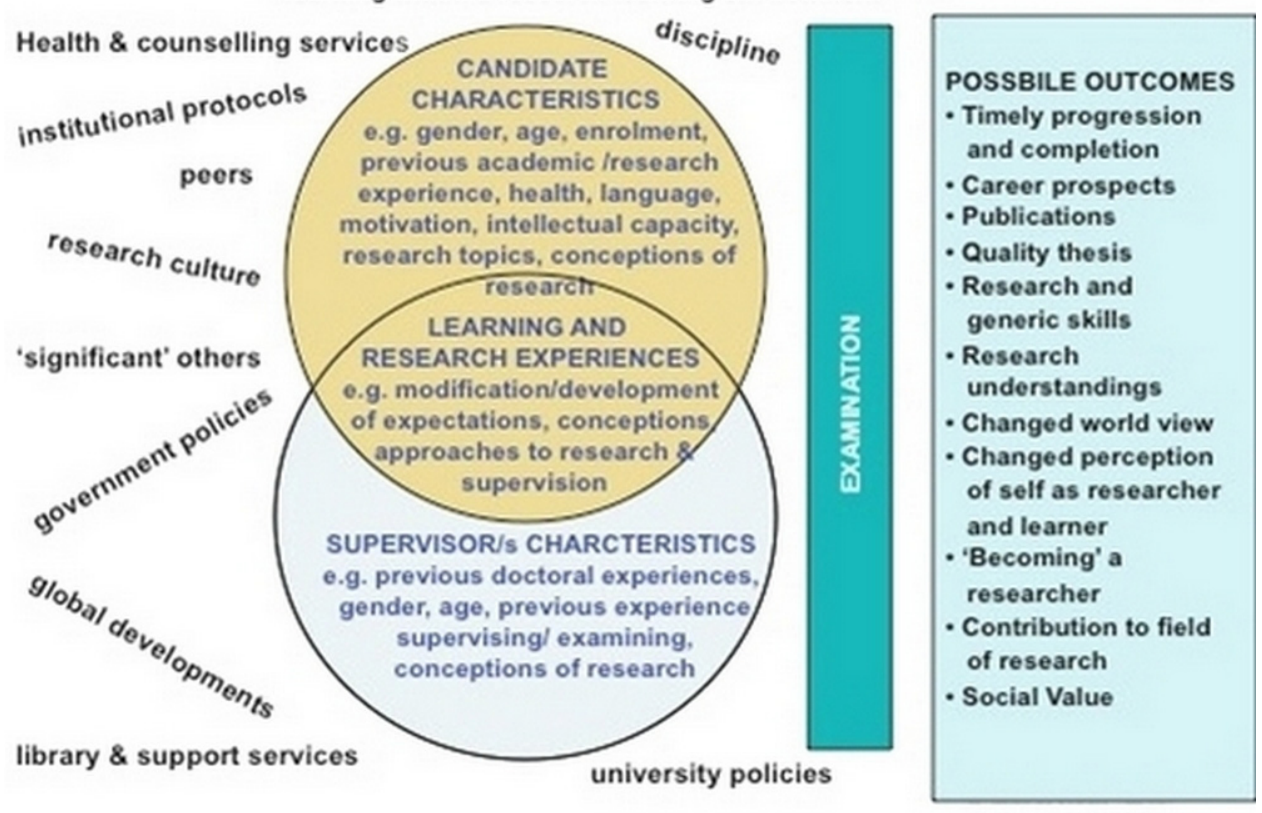

Fig. 1. A model of influences on the doctoral curriculum [1].

It has been well documented that students in science based faculties have greater satisfaction with their candidatures than humanities students, as the science projects often have some laboratory-based component, often more of a team atmosphere and more opportunities for interactions with supervisors, staff and other students and the results here were consistent with previous reports.

Another observation was international students have greater 'agreement' with all scales (with lower agreement with 'infrastructure' and 'research climate') than domestic students. The data provided does not account for this observation and the underlying factors at this stage could only be the subject of speculation.

The quality of the research climate has been shown to be an important part of the research experience and has a role in optimizing output and minimizing student attrition during their candidature. On reflecting on this data the authors make some suggestions. Organizing student review and feedback on the items of the SREQ, including what items they would suggest modifying, omitting or adding and why, and how the changes may have a positive effect on their candidatures.

This exercise could also be utilized to investigate the 'research climate' items and students' perceptions on the importance of these items and why a neutral response to these items is more prevalent than items of other scales [10]. 


\section{Research training curricula}

Order of the Ministry of Research and Education of Romania no. 4491/2005 06/07/2005 Published in the Official Gazette, Part I no. 589 of 07/07/2005, regarding the organization of doctoral studies in the academic year 2005/2006, inter alia, provides: “....PhD is a distinct type of learning and research, allowing doctoral students to obtain both peak powers in the specialized field of study and personal and managerial skills generic:

a) develop research projects in order to obtain the resources to finance them;

b) discover innovative solutions and communicate them effectively;

c) ensure good management of time and resources involved in research;

d) continuously monitor the quality and performance in their own work and the work of the team belongs."

Therefore neither this time, nothing about research training curricula, only sequence of "competences" whose assessment methods are mainly subjective, at theirs supervisor discretion.

Because the job of scientists to be attractive for junior researchers, the employment conditions and payroll are some particularly important. Although in Romania of 0.2 percent of GDP for R\&D activity is insufficient, recent statistics show that research expenditure structure is a well balanced one both the performance sectors (figure 2) and the types of research (figure 3) [11]. We can say that the will is there, the structure is healthy but content of training researchers is deeply deficient through curricula that do not offer the support required.

\section{Struc ture of total expenditure from research - development activity; by sectors of performance}

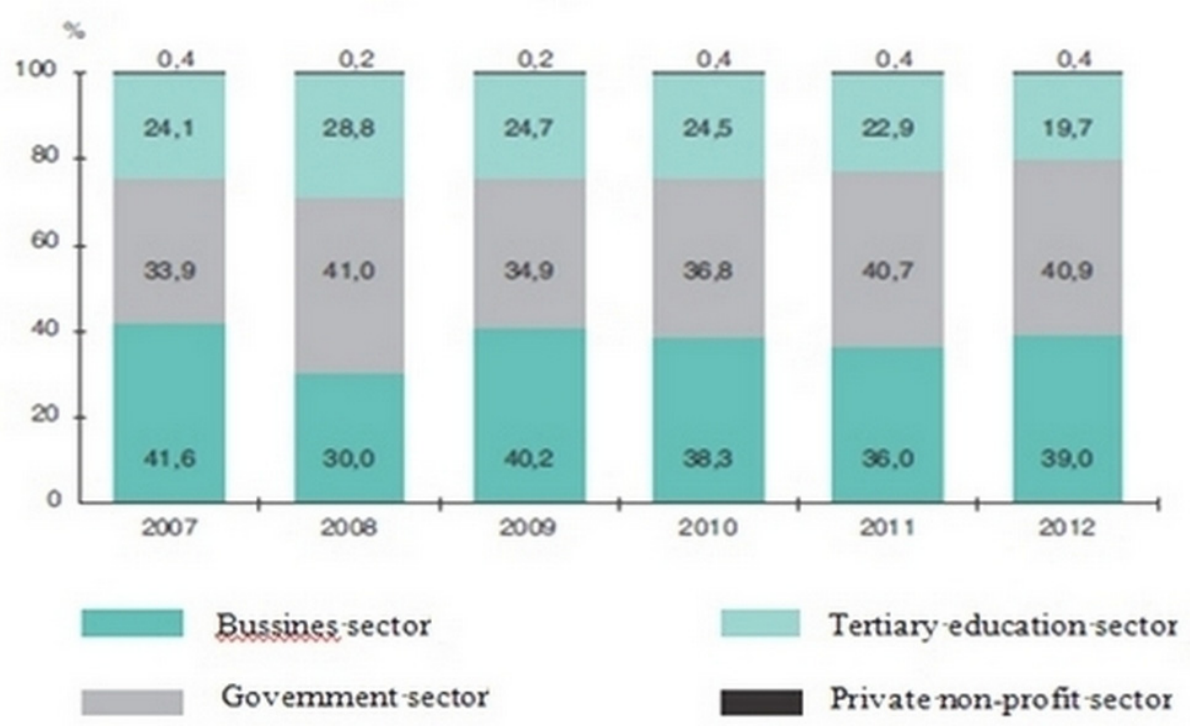

Fig. 2. Structure of total expenditure from R\&D activity, by sectors of performances ( Romanian Statistical Yearbook 2013).

In support of better understanding the role that it is preparing the master's and doctoral researcher training in the field of engineering, the authors examined in a comprehensive review of both literature and the requirements of employers, the following: the characteristics that must possess researchers from academia and manufacturing, their training and their work 
environment. Analyzed areas should be developed by faculty and departments dealing with assessment, career development, professional socialization, organizational development, higher education and in research and development enterprises.

The results obtained show that, in addition to terms of knowledge and skills in an area of research, scientists successfully values and attitudes derived from the specific experiences of socialization academic, the significant support given by mentors and colleagues or the organization of activities their research department.

\section{Current expenditure from research - development activity, by type of research}
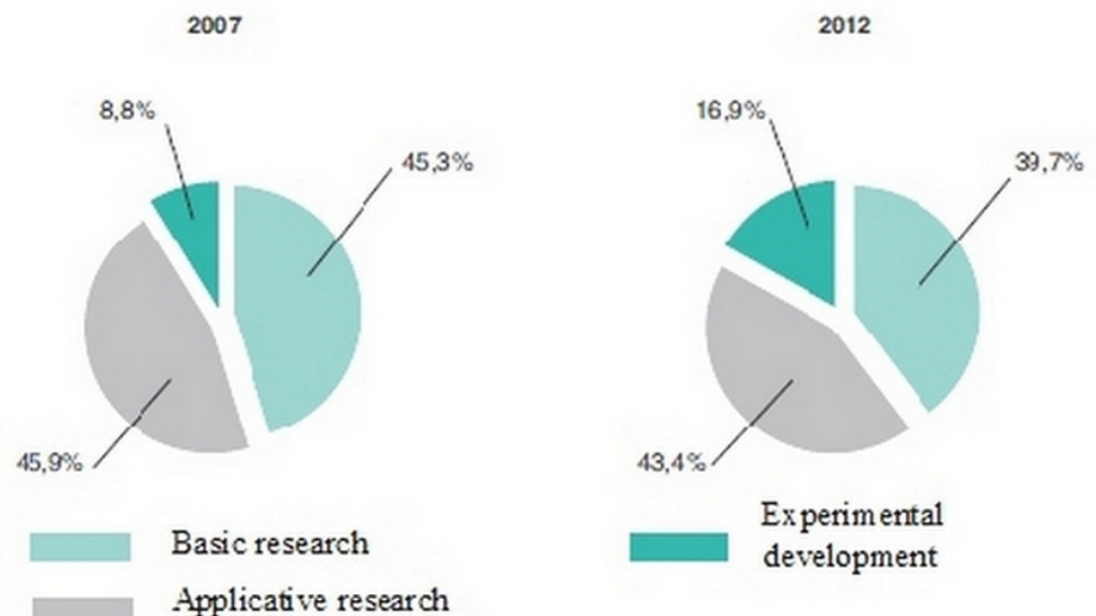

Fig. 3. Current expenditure from R\&D activity by type of research ( Romanian Statistical Yearbook 2013).

A review of these studies [12] has highlighted substantial variation in academics' views of research, in terms of their:

-research intentions-who is affected by the research;

-research outcomes-the anticipated nature of the effect;

-research questions-the nature of the object of study, and

-research process-how research is undertaken.

As a group, these studies have shown that academics do not necessarily agree on what it means to be university researcher, to conduct research or to be successful in research.

Furthermore, such variation in views of the nature of university research has been shown to occur:

-within disciplines as well as across disciplines;

-within research intensive universities as well as non-research intensive universities;

-amongst senior academics as well as early career academics.

\section{Conclusions}

We manifest our concern that in Romania today researcher or professor and research worker operates out of the concerns for which was prepared. This divergence is likely to lead to an irrelevant theory and practice unauthorized and invalid. Such results will damage the 
reputation of universities as trainers of researchers and ultimately will lead to our extinction as caste.

The authors also suggest that both academic unit personnel and students need to be made aware of the importance of the research climate and all must take some collective responsibility to maintain and enhance this climate. Academic unit staff may need regular reminding of the importance in instigating and supporting research climate activities and students may require induction into what a research climate is, why it is important to them and how they can take an active contributory role in its maintenance. Furthermore it would be useful for the institution or academic units to assist master and doctoral candidates to develop strategies to deal with some of the regular issues that arise when working within a competitive, somewhat constrained and bureaucratic environment with regular workshops on these issues with successful established researchers.

\section{References}

1. N. Hopwood, D. Boud, A. Lee, M. Abrandt Dahlgren, M. Kiley, Proceedings of $9^{\text {th }}$ QPR conference, Educating Researchers for the $21^{\text {st }}$ Century, 83 (2010)

2. K. H. Campbell, Democracy\& Education 20, 7 (2013)

3. B. Berg, Qualitative research methods for the social sciences (MA: Allyn \&Bacon, Boston, 2001)

4. M. Cochran-Smith, S. Lytle, Inside/outside: Teacher research and knowledge (NY: Teachers College Press, New York, 1993)

5. R. Hubbard, B. Power, B, Living the questions: A guide for teacher-researchers (ME: Stenhouse, New York, 1999)

6. R. Shagoury, B.M. Power, Living the questions: A guide for teacher researchers ( York, ME: Stenhouse, 2012)

7. L. Shulman, L., Autonomy and obligation. ( NY: Longman, 1983)

8. J. Duffield, S. Townsend, Action in Teacher Education 21, 13-20 (1999)

9. M. Simms, Democracy\&Education, 21(2), 3 (2012). Available online at http://democracyeducationjournal.org/home/vol 21/Iss2/3

10. M. Govendir, B. Govendir, Proceedings of $9^{\text {th }}$ QPR conference, Educating Researchers for the 21 st Century 13-15, 65 (2010)

11. www.immromania.ro/a-aparut-anuarul-statistic-al-romaniei-2013-7639.htm

12. G. S. Åkerlind, Higher Education 55, 241 (2008) 